\title{
Discussion to papers of K. Steinbrück, B. A. Green, J. Kiwerski, V. G. Gaspar, E. L. Griffiths, H. L. Frankel, Girard, Ohry and Melamed Sir GeORge BeDBrook, Chairman
}

Dr MAURY (France) (translated by Dr Dollfus). The first point is that it is not necessary for the diver's head to touch the bottom of a lake. Three out of 20 cases we got actually were hit by a wave. He quotes the work of Schneider in Acapulco who had made X-rays of 5 divers and found fractures of the cervical spine. The second point he would like to make is that wounds of the face are extremely rare in diving accidents and only 2 out of 20 patients had such wounds. The third point is that it is extremely difficult to reconstruct the mechanism of the injury. We see from X-rays afterwards that there is hyperflexion or hyperextension fractures but we are never sure and even in tear-drop fractures we are never sure of the proper mechanism of the bony lesion. The last point concerns the sensibility. In 6 or 7 cases out of 20 there was dissociated sensory disturbance of syringo-myelic type and some of them are due to disc protrusion, the others were due to a lesion of the anterior spinal artery or also probably due to lesion of the vertebral artery.

Dr Paul Meyer (U.S.A.). I would like to ask the authors if they might give some thought to the question that I raised thereto. Very often patients relate that they were not initially tetraplegic, and I am always impressed by the few that succumb from diving injuries and the large number that survive, and because of that I always question very carefully how much did they feel immediately following the injury and what portion of their body did they feel immediately following the injury and what portion of their body did they use to ascend in the water. I am concerned that we are dealing with patients who are not complete injuries but during the extrication become complete and I wonder what the authors have found.

Professor WeISS (Poland). We did the same investigations as you and we had the feeling that 50 per cent of our cases were not paralysed at the moment when they hit the bottom. They are paralysed when the stability of the spine is damaged, and all their cries to others to bring them out are made. And if you ask them 'Did you move your legs during the movement in the water' they may answer yes, but of course it is impossible to be sure of that. Another group we found was damaged during the manipulation to get water out of their lungs.

DR A. HARDY (G.B.). In the vast majority of cases in my experience the violence extended on the cord was maximal at the time of injury but we are concerned with what happens when the violence is minimal. I would like to ask a question and make another statement that in those cases in which there is minimal violence we must remember that oedema and haemorrhagic necrosis take time to appear, and in the experimental method haemorrhagic necrosis may take up to 4 hours before it is fully developed. Now when people say that mismanagement has occurred in the case of a minimal lesion, it is important to remember the time factor, that there may be occurring oedema and most certainly haemorrhagic necrosis which people may attribute to mismanagement. It is therefore very important for the authors of these papers to state what criteria they use for the assessment of the neurological regression before admission to hospital. I would like to ask whether this was a factor which was observed in the second paper, what criteria were used other than the patient's testimony?

SIR GeORGe BeDbrook. The second paper was given by Dr Green, would he like to answer that question?

Dr BARTH GrEen (U.S.A.). I am sorry to say that it is just the patient's testimony. That we had the same experience as Dr Maury had that people would tell us when they were removed from the water that initially they could move and they were flicked over and dragged over the side, and by the time they reached the hospital they were unable to 
move. Whether this is the natural pathophysiology, the haemorrhagic oedema or whatever, is possible, but we are much more apt to feel that it is secondary injury.

DR P. Doll Fus (France). I would like to say that one of our patients with a complete tetraplegia, admitted to the Traumatology Unit at Colmar, that he was transported by his friend in a car in a sitting position after the accident, so I dread to think what must have happened when he was dragged out of the water.

MR MCSweEney (G.B.). I submit that while we all agree that this is a fact we believe in, I don't think it would stand up in a legalistic approach, in other words, despite our feelings and our beliefs I still think we are lacking in hard evidence that neurological deterioration is a common feature in these injuries. It is very easy for the patient to say 'my limbs were moving', simply because he had been supported by water and it is equally easy in transportation particularly again in this medico-legal context where the patient has said that he was moving his limbs before the ambulance arrived on the scene.

MR P. HARRIS (G.B.). Regarding these papers, on the X-rays that we saw, I think on, gross lesions; I wonder if any of the patients had no obvious X-ray change. The second point is; did any of the patients with gross X-ray changes show minimal or no neurological abnormality? Then like the others I would go along with this problem of knowing that the patient in fact did have neurological function and that this was disturbed, because they seem to be different, and if the point brought out by Dr Hardy which is very important, about 4 hours to develop a lesion. Finally could I ask did any of these patients have head injury? Dr Maury mentioned facial injury, I wondered about head injury. I've never seen this.

DR GREEN (U.S.A.). Our patients had head injuries but not loss of consciousness. They had bruises on the forehead and vertex of the skull but we were amazed that the majority did not lose consciousness, and I believe that is the answer to one question, so we did have serious head injuries as part of the dive. We did have patients with spinal cord injuries without spinal fractures but these were in the minority.

DR H. FRANKel (G.B.). We did not pick up a large number of delayed onset of spinal cord lesions. We are in the centre of Britain far from the sea so all our sea cases come to us with at least a few hours delay, and we are not in the richest part of the country so there are not many swimming-pools, so almost all of our patients arrived after a delay of at least a few hours. Nor did we find a definite pattern of injury from other causes. There were rather more pure dislocations in this group than we find elsewhere. With regard to the spinal examinations, I believe that a substantial number of these patients do drown and are not then described as spinal injuries at all, they are described as drownings. Of those who are pulled out of the water, they have to be pulled out of the water or they will drown, so I don't think we are going to improve first aid. Removal from the water will always have to be done by whoever is available and if you want to train every person who is going to save someone from drowning, that the patient might also have a broken neck, I think you are going to spread a certain amount of anxiety amongst the general population.

Sir GEORGE BEDBROOK (Australia). May I just make a comment. We get all our cases very early and we cannot say that we have seen any patients who have come to us with movement who have then lost it. The second thing is that undoubtedly they do drown because we've seen them in our post-mortem series.

DR J. Grant (Australia). I actually would like to make a couple of comments. Firstly, I think that I would agree with $\mathrm{Mr}$ McSweeney that I doubt whether this question of positive movement would actually stand up to a very detailed examination. Scanning of the cervical spine is probably one of the most useful new major investigations that has come our way. But I think it should be combined with one of the more soluble contrast media and it will tell you a great deal about the nature of the injury, the contents of the canal, which you cannot learn by clinical examination or by ordinary X-ray or by tomography, and I think that particularly in partial lesions $\mathrm{C}_{2}$ scanning will tell you whether it is a lesion anteriorly, and I think that if possible this method of investigation should be used in all cases if you are lucky enough to have such instrumentation available.

SIR Ludwig GutTmanN (G.B.). I was a little surprised that with the exception of 
Dr Frankel none of the speakers or discussants mentioned how these injuries can be prevented, and this is of course where our Society comes in. Frankel quite rightly said that Dr Penny, the doctor interested in sport, has succeeded at least to diminish these terrible injuries which befall mainly young people in swimming-pools. In previous sessions of the Society I have been concerned for some years with preventive measures. I think unless we start very early with the education of children we will never succeed. When children start swimming at the age of 5 or so, that is the time when we should start to teach the children how to prevent these injuries and that can be done in the same way as schoolchildren are taught how to cross from one side of the street to the other. Resulting from the many lectures I have given on this subject to people concerned with Baths Management, and I can say that in Britain at least we have prevented quite a number of injuries in swimming-pools. There are two types of injuries in the swimmingpool, either the person dives and hits the head against the floor, which is a very common thing. The other is that he dives on to a swimmer in the water and causes a thoracic injury to the swimmer, as this happened to one of our members, Alain Rossier; or the diver sustains a cervical injury. I think we also have succeeded to some extent to prevent these injuries in swimming-pools by teaching the coaches and other people responsible, but we have not succeeded to persuade Educational Authorities to take the same serious view with the education of children in this respect. It is absolutely necessary to erect warning signs along the coast where people are bathing. These should be arranged by the local authorities concerned. In view of these excellent papers, our Society should collect all the data and make an official approach to Governments in various countries, and I think this might succeed to improve the situation. It is really terrible, if a young boy of 15,16 or 17 dives into shallow water and is transformed in a nick of a second from a healthy individual with great prospects for his future into a helpless wreck. There is where our Society, with its great experience, could be of great help to educate the public and educational authorities about the dangers of diving.

SIR GEORGE BEDBRooK. I'd just like to comment on what Dr Grant said. There is no question that the C.A.T. scan is of value, but as yet I don't think anybody has published any work as to its value. If Ellis Griffiths were here, he would want me to say that he has been conducting a continuing investigation where 40 patients have now been investigated. We are convinced on very critical examination that in only one of those patients was the C.A.T. scan really valuable, but it's too early yet to make statements.

Dr GEISLER (Canada). Where I think the author is able to determine from their analysis of the data whether the attitude of the patient's arms applied at the time of the dive, that is, whether or not they were extended acted in any preventative sense.

Sir GEORGE BEDBRook. Well I'd just like to say since most of ours were from the surf that we have absolutely no idea where the arms were. Would any one else of the authors like to answer that one?

Dr BARTH GREEN (U.S.A.). Just to say with regard to arms, several of ours have encountered a slippery surface, that they did have their arms extended and they hit the bottom in the above-ground type of pool, not the underground type pools, and they lost control of their hands and hit their head.

Professor WeIss (Poland). During my evaluations I found that when they touched the ground within a river with their hands flexed, they get a reflex and they move the hand away and that is why they hit. All our divers are jumping into water with hands forward but they get reflex from the hands, the hands go away and then the head gets hit, so I understand.

DR J. Young (U.S.A.). In recent years, the clinical entity of fresh-water drowning has been addressed by our pulmonar physicians and it is the special problems associated with filling the lungs with fresh water and then the massive pulmonary oedema that occurs subsequently. This superimposed damage on tetraplegia indeed presents a serious clinical management problem. I would like to ask one of the authors to comment on the special measures they took in the pulmonary management of these people in the acute post-injury period.

SIR GEORGE BEDBROOK. I can only say from experience that we have had, that the 
pulmonary problems are quite extensive, that we get those with sea water rather than fresh water and this is even worse.

Dr GREEN (U.S.A.). The cases we reviewed were from fresh-water pools and a lot of them had aspiration pneumonitis which wasn't immediately apparent as a serious problem. Within 24 to 48 hours they developed serious deterioration and required intubation.

DR GIRARD (France). I would like to comment and ask the authors about one thing. I had to review last year for the medical doctors specialising in sports medicine, sports accidents, spinal cord injuries, our cases of diving accidents. Out of 25 only one was a sea accident. Our Centre is located in the centre of France but anyway we get all patients and it is very easy for us to go to the South. We get all patients after a while to our Centre so sea accidents seem to be rare. We have no accidents in swimming-pools. Our diving accidents occurred in lakes and rivers like in Poland and Germany and it is a sort of wild diving and not in swimming-pools where there is always a coach or somebody on guard. Now our beaches are controlled by lifeguards or some teachers or coaches but with these accidents in rivers or lakes, prevention is extremely difficult and we have no possibility of prevention.

SIR GEORGE BEDBROoK. I think the real issue about prevention is that of education isn't it?

Dr P. Meyer (U.S.A.). I'd like to respond to several things that I've heard from several different people including the authors. One is from an academic standpoint. I think that most of us are involved in the evaluation of computerised tomography, not that we believe that it is the only way to go but that we really don't know yet how to interpret it from the standpoint as clinicians in the field of spinal surgery for which reason we perform in all patients C.A.T. scans and tomography. Tomography is far more revealing than the C.A.T. scan is, except in the patient where you are looking at a piece of fragment which is lying in the canal and you would like to know exactly where it is, and again I think you can find that from a C.A.T. scan better than you can from a tomogram, but none the less a tomogram will reveal more of the injuries present over several levels. Now with reference to the use of Matricimide, I think you should be cautious in the use of Matricimide in any patient who has an incomplete lesion in the cervical spine. Matricimide is known to produce seizures when used in the cervical spine and if you have a patient with an incomplete neurological lesion, following the use of Matricimide you may end up with a seizure and with a seizure you may end up with a complete lesion and then you stand in jeopardy as to the reason why you used Matricimide. There is no question as to whether or not there are a number of these patients who reveal some neurological function and then after being removed from the pool end up as a complete injury. I was discussing a moment ago with Dr Hardy and McSweeney this question and I am convinced now that there are more patients becoming incomplete by the care that they are receiving, knowing the individuals performing the initial neurological examination and knowing the Residents who have been adequately trained, I am finding in our patients a higher incidence of patients who were categorised initially as complete who then become incomplete. Not that there is functional motor return but representative of some function below the level of the lesion. The point is that these patients are the same patients who report in the pool that they may have noted something present before extrication. You may have some comments to that.

To SIR LUDwig. There is a great national effort in the United States in education. I think that every Federally sponsored spinal injury programme is now involved in a major thrust in prevention and Dr Henry Betts who is Medical Director and Professor of Physical Medicine and Rehabilitation at Northwestern may at some point come in on the major thrust in prevention which his programme is serving. The other comment by $\mathrm{Dr}$ Barth Green on the above-ground pool: we have presently in our spinal cord unit 13 acute injuries in the last 2 weeks; 3 of them have resulted from above-ground swimming-pools and they should be, just like trampolines, eliminated from the pool category. From the pulmonary standpoint, we have found pulmonary complications in all of our tetraplegics, and I really doubt seriously if it is related to aspiration. For the same reason that almost all 
of these kids have been resuscitated without difficulty at the pool side and most of them have been able to hold their breath, most of them have been extricated in very short periods of time, none of them have sustained cerebral injury as a result of annoxia or hypoxia and almost all of them have pulmonary complications when they are high tetraplegics.

SIR GEORGE BEDBRook. I regret to say from the Chair I can't agree with you about the latter statement because that may be so in your environment but certainly not in ours. There is no question about the head injury and I don't think there is any question about the pulmonary aspiration.

Dr FreEd (U.S.A.). Perhaps Bostonians enjoy the fruit of the vine more than people in the rest of the world, but in the last 50 diving accidents a significant number, almost 90 per cent have been associated with alcohol consumption. So I submit that obtaining a decent history is most difficult. These have all been good divers, have been taught for many years; but this was done at a party or after a party, going into the shallow end of the pool or a goldfish pond.

ProfESSOR WeIsS (Poland). I am absolutely with Sir Ludwig concerning education. I would like to share with you my Polish experience in educating the public. I have an official State programme about this particular accident which is composed of three things. Twice a year we get a half-an-hour television programme where we present tetraplegics' stories of how this tragedy happened. Secondly, my Society of which I happen to be President, created a set of slides with a description for schools and we give them free to all schools in the country, where in an education programme, these things are repeatedly shown, and the third programme is that the Sports Ministry has created special rules for training coaches in saving people. As I said to you, I had mostly river accidents and lakes and I agree with my colleague calling from Boston, that particularly in my country alcohol is an additional factor. We lost most of our cases of cervical spine due to pulmonary complications.

Mr MCSWEENEY (G.B.). Just a small point Mr Chairman to remind members that in Richard Schneider's original paper on the Acapulco divers, he did mention one factor of prophylaxis and if I may demonstrate, it was to keep the hands locked above the head. Schnieder pointed out that there were very few acute in the divers and reminded us that the prophylactic action was to develop the muscles of the shoulder girdles and to lock the hands above the head.

DR H. Frankel (G.B.). Regarding the pulmonary complication, we don't find pulmonary complications frequently in tetraplegics who are injured on dry land, without any other injury. We don't find it in the trampoline as we do in the divers and we believe that a significant number do inhale the water in which they dive. I disagree with the Chairman, I believe that fresh water is more immediately lethal than sea water.

Sir George Bedbrook. Not with sand. Ladies and gentlemen we've had a most stimulating discussion. I am sure that from all this discussion, however, comes one major problem point, and that is that we ourselves have got to do a great deal more about prevention, and in summing that up, it is a question of a multifactorial approach. It is not a question of a vaccine, it's a question of education and that we have got to take up the whole problem of education, and I am sure that with that we will see the results over a period of another 5 or 6 years.

\section{After lunch session}

DR HAMzA (Egypt). I would like to ask the author of the first paper who mentioned that in most of the patients residual disability was impotence, was there any indication of other disturbances than just impotence?

DR GIRARD (France). Men who improved without any other troubles rarely had sexual impotence. Those who had urinary trouble had sexual impotence.

Dr Meisel (U.S.A.). Either of these gentlemen, could you say something more about timing as far as decompression regarding long distance transport of these people.

SIR GEORGE BEDBROOK. To decompression units?

Dr MEISEL (U.S.A.). I am thinking of two cases in California that were very far $\mathrm{I} 8 / 2-\mathrm{E}$ 
from decompression units and the question arose as to whether to send them when it had been too late when it was diagnosed in the remote area. How long after?

DR GIRARD. Decompression within 6 hours. We have got a lot of decompression units in Southern France and even in Corsica there are special units, so they are rushed to these units and there is a rescue system. I think now they arrive in the units less than 6 hours after the accident, maybe 2 hours. That's much better than 6 hours.

Dr Frankel (G.B.). Could I ask Dr Ohry to confirm that when he sends his patients by helicopter they are in a chamber while in the helicopter.

DR OHRY (Israel). Yes, they are quickly sent by the army, we have no civilian helicopters for this purpose in Israel. They are taken very quickly to that big chamber in Haifa and the patients are in the small chamber during the transport.

Professor WeIss (Poland). My question is to my colleague from Tel Hashomer. Did I understand well that due to this hyperbaric treatment you get such high incidence of recovery in complete neurological cases. What is really the result?

DR OHRY. We had only two pure spinal patients, one was a complete $\mathrm{C}_{5}$ tetraplegic and now more than 3 years after the accident he is incomplete. The other a Spanish tourist who had his injury in the Red Sea, he is cauda equina complete and remained cauda equina. He didn't respond to treatment.

SIR GEORGE BEDBRook (Australia). I would like to ask a question of the authors. What is the risk in a professional diver who has had one episode of transitory paraplegia of a further episode occurring going back to professional diving?

DR OHRY. I think that it's now a rule; once you have had decompression sickness you never dive again. I think that's the ruling internationally.

SIR GEORGE BEDBROoK. Well I'd like to thank the authors for two very interesting papers on a very important subject as far as we are concerned and obviously there has been a tremendous reduction in this disease over the last 40 or 50 years because of the very strict international rule, and I think that only gives a pointer to us to what we talked about this morning, how prevention is certainly going to give us better results. Thank you very much. 